\title{
Preparation of cubic-shaped sorafenib-loaded nanocomposite using well-defined poly(vinyl alcohol alt-propenylene) copolymer
}

\author{
Tivadar Feczkó, ${ }^{\mathrm{a}, \mathrm{b}}$ Gabriella Merza, ${ }^{a}$ György Babos, ${ }^{\mathrm{a}, \mathrm{b}}$ Bernadett Varga, ${ }^{\mathrm{a}, \mathrm{b}}$ Eszter Gyetvai, ${ }^{\mathrm{a}}$ László Trif, ${ }^{\mathrm{a}}$ Ervin Kovács, ${ }^{a}$ Robert \\ Tuba $^{a^{*}}$ \\ a. Institute of Materials and Environmental Chemistry, Research Centre for Natural Sciences, Hungarian Academy of \\ Sciences Magyar tudósok körútja 2., H-1519 Budapest, P.O. Box 286, Hungary. \\ b. Research Institute of Biomolecular and Chemical Engineering, University of Pannonia, Veszprém, Egyetem utca 10., H- \\ 8200 , Hungary.
}

Vinyl alcohol (VA) copolymers having fine tunable polarities are emerging materials in drug delivery applications. VA copolymers rendering well-defined molecular architecture $(\mathrm{C} / \mathrm{OH}$ ratio $=2,4,5$ and 8) were used as carriers for model drug compound, fluorescein exhibited significantly different release characteristics depending on the polarity of the polymers. Based on the preliminary drug release tests the well-defined VA copolymer having $\mathrm{C} / \mathrm{OH}=5$ ratio, poly(vinyl alcohol alt-propenylene) copolymer (PVA-5) was selected for nanocomposite synthesis. Sorafenib anticancer drug was embedded into PVA-5 (C/OH $=5$ ratio) nanoparticles by nanoprecipitation resulting in nanoparticles exhibiting unusual cubic shape. The sorafenibloaded nanocomposites showed continous release during a day and concentration-dependant cytotoxicity on HT-29 cancer cells. This might be interpreted by the sustained release of the drug.

\section{Introduction}

Physiological processes at the molecular level occur at specific space and time scales, which are different for every tissue predetermining the need for the carriers that allow tunable drug release.(Uskoković and Ghosh, 2016) Metals, polymers, ceramics and bio-derived materials have been studied and used as medical implants.(Prakasam et al., 2017) Such materials can be designed for a wide range of biomedical applications, e.g. controlled drug delivery devices (Park, 2014) and tissue engineering constructs.(Uskoković, 2015) However, these materials should possess the ability to be tunable to exhibit complex kinetics of therapeutic molecules' release. Overall, there is a need for the development of sensitive and smarter controlled release carriers in pharmaceutics.

Fluorescein (Fig. 1. a) is a chemical dye having several medical application. It has been approved by the Food and Drug Administration (FDA) of the U.S. Department of Health and Human Services since 2006.

Sorafenib (Fig. 1. b) is a multikinase inhibitor acting at tumor angiogenesis and proliferation. It is the exclusive drug approved by the FDA against advanced hepatocellular carcinoma (HCC) which is the fifth most common malignant cancer in the world and the third most frequent trigger of cancer-related death.(Hsu et al., 2017) HCC resistance to chemotherapeutic agents is especially high. The efficiency of sorafenib on tumor elimination is low most likely because of drug resistance that has substantially limited the overall therapeutic effect of cure. In addition, many patients suffer from multiple side effects.(Long et al., 2017) Consequently, the development of sustained drug delivery systems to improve the bioavailability of sorafenib is an important nanopharmaceutical task.

\section{Insert Figure 1 here}

Polyvinyl alcohol (PVA) has been widely applied in drug delivery application in various forms, such as films,(Stampella et al., 2013)'(Gan et al., 2016) hydrogels(Sakai et al., 2013), nanofibers,(Mahanta and Valiyaveettil, 2012) membranes(Manasco et al., 2014) and nanocomposites.(George et al., 2012) In composite nanoparticles generally hydrophilic drugs are incorporated by PVA.(Malarvizhi et al., 2014) In another approach sorafenib, the anticancer drug was loaded into PVA-coated superparamagnetic iron oxide nanoparticles.(Tom et al., 2018) To our knowledge lipophilic PVA has not been used for the preparation of nanomedicines. Drug delivery applications can benefit from tuning the polarity of PVA copolymers so that they can be used in the regulation of controlled drug release.(Santos et al., 2018) The polarity of the well-defined PVA copolymers can be adjusted by changing the density (i.e. $\mathrm{C} / \mathrm{OH}$ ratio) of the hydroxyl groups along the polymer chain.(Su, 2013)'(Tuba et al., 2016)

The polymer hydration properties can be modified by the introduction of polar functionalities on the polymer backbone. The type and the density of the polar substituents can significantly affect the hydration properties and so indirectly the embedded drug release rate.(Ghori and Conway, 2015) Different polar substitution density allows different water mobility thus different drug release characteristics.(RajabiSiahboomi et al., 1996) The substituents of a polymer side chain alter its polarity and its melting point. For instance, substitutions of the side-chain groups by more polar groups result in a reduction in the crystallinity of the polymer, which is reflected in a decrease in its melting point. This affects the solubility of the polymer in water.(Sarkar and Walker, 1995) The number of hydroxyl groups has an impact on the polarity of the polymers used as drug carrier which can have a great effect on the drug release, as well. 
PEVA (poly (ethylene-vinyl acetate)) as copolymer of ethylene and vinyl acetate is often used in biomedical engineering applications as drug delivery matrices. The synthesis of PEVA via radical co-polymerization of ethylene with vinyl acetate leading to VA copolymer derivatives are well-known.(Okaya, 1993) Cationic group-transfer polymerization(Mori et al., 1994) and palladium-catalyzed ethylene-vinyl acetate copolymerization(Ito et al., 2009) are also reported. These reactions result in polymers exhibiting randomly distributed polar and non-polar dyads. However, reports on the synthesis of VA copolymers exhibiting well-defined molecular architecture are rare.(Li et al., 2013; Scherman et al., 2002; Tuba et al., 2014; Valenti and Wagener, 1998)

The specific structural characteristics of PVA and VA copolymers originating from the sequencing (primary structure) of monomeric units, as well as the configurational and conformational assembly of the secondary structure, affect the drug delivery properties of the carrier material. The key aspect in these cases is the relative balance between the functional groups (structure, relative concentration, and position in the repeating unit) and the overall hydrocarbon content of the repeating units, as well as their arrangement in homopolymer or copolymer structures.(Pajak et al., 2010) The biodegradation of PVA was investigated by several research teams using different types of microorganisms over the past decades. Pseudomonas microorganisms can degrade the polymer by the mechanism through secondary alcohol oxidase (SAO) and $\beta$-diketone hydrolase (BDH), using specific dehydrogenase of PVA observed in Alcaligenes faecalis KK314 strain.(Chandra and Rustgi, 1998; Chiellini et al., 2003; Pajak et al., 2010) The biodegradation of VA copolymers is fostered by hydroxyl functionalities of the polymer chain.(Chandra and Rustgi, 1998)' (Pajak et al., 2010)

When the VA-copolymers are synthetized by olefin metathesis polymerization the distribution of the $\mathrm{OH}$ groups along the well-defined VA-copolymer chain can be predetermined unlike in case of the random structured PEVA produced by radical polymerization.

Well-defined VA copolymers can be synthesized by ring opening metathesis polymerization (ROMP) or acyclic diene metathesis polymerization (ADMET) reactions using welldefined Grubbs, ruthenium-based metathesis catalyst systems (Fig. 1. c). ROMP is a chain-growth polymerization process where strained cyclic olefins are converted to a polymeric material. ROMP reactions are driven by the release of ring strain from the monomer(s) (e.g. cycloolefins). ADMET is a step-growth polymerization, which involves the elimination of small molecules such as ethylene (Fig. 2.).(Sutthasupa et al., 2010)' (Wagener et al., 2006)

\section{Insert Figure 2 here}

In general, molybdenum and tungsten catalysts are relatively sensitive to oxygen-containing functional groups including alcohols, aldehydes and carboxylic acids. Nevertheless, ruthenium metathesis catalysts are rendering high functional group tolerances.(Balla et al., 2016) Earlier studies reported the ruthenium catalyzed ROMP of hydroxyl functionalized cyclooctene resulting in linear hydroxyl-functionalized polyoctenamers.(Hillmyer et al., 1995) The synthesis of welldefined ethylene-vinyl alcohol copolymers was reported by the
ADMET of two vinyl acetate-containing symmetrical $\alpha, \omega$-diene monomers (Li et al., 2013) and also introduced primary, secondary and tertiary hydroxyl groups in precise intervals into the polyolefin chain.(Valenti and Wagener, 1998) By the ROMP of a "temporary" strained cis-4-cyclopentene-1,3-diol poly(vinyl alcohol ${ }_{2}$-alt-methylene) was synthetized under forcing conditions.(Scherman et al., 2002)

In this study well-defined VA-copolymers (Fig. 3.) with finetuneable polarity have been investigated as potential drug delivery materials for pre-programmed drug release. VA alternating copolymers have been synthetized via olefin metathesis reactions by the ROMP of cyclooct-4-ene-1ol(Martinez et al., 2014a) and cyclooct-5-ene-1,2-diol (Scherman et al., 2005) and ADMET of 1,6-heptadiene-4-ol according to standard literature procedures.(Tuba et al., 2014) The formed polyolefins were hydrogenated by $\mathrm{Pd}$ on carbon giving the target VA copolymers in quantitative yield. The yields, the polymers' molecular weights $(\mathrm{Mw})$ and dispersities (Đ) summarized in Table 1. correlate well with the data found in the literature.(Tuba et al., 2014)(Martinez et al., 2014b)(Scherman et al., 2005)

\section{Insert Figure 3 here}

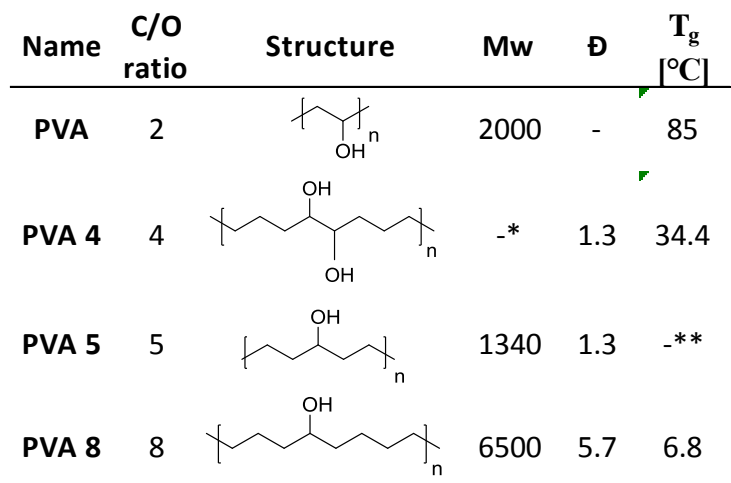

Table 1 The GPC analysis ( $\mathrm{Mw}, \oplus$ ) and glass transition point $\mathrm{T}_{\mathrm{g}}$ values of the PVA co-polymers used in controlled drug release experiments *PVA-4 was insoluble in THF, no GPC data was obtained. ${ }^{* *}$ PVA-5 has crystalline structure, no $T_{\mathrm{g}}$ data was obtained

Herein, we report the sustained release of fluorescein and sorafenib using well-defined vinyl alcohol copolymers having high content of precisely-spaced vinyl alcohol functionalities. The fluorescein model compound has been selected for preliminary drug release investigations, as its logP value (3.4) is similar to that of the sorafenib (3.8). In the preliminary experiments fluorescein has been embedded into a series of well-defined VA copolymers. Based on the drug release tests, the most promising VA copolymer was selected as a nanocarrier for sustained sorafenib anticancer drug release. VA copolymer-sorafenib nanoparticles have been synthetized by nanoprecipitation and subjected to in vitro studies including biorelevant drug release test, cellular uptake - and cytotoxicity investigations with HT-29 human cancer cell line. 


\section{Materials and methods}

Poly(vinyl alcohol)- (PVA, Mw=30,000-70,000, 87-90\% hydrolysed), polyoxyethylene sorbitan monooleate- (Tween 80) and Pluronic F68 emulsifiers; ethanol, acetone, dimethyl sulfoxide (DMSO), sodium azide, 1-ethyl-3(3dimethylaminopropyl) carbodiimide (EDC), Nhydroxysuccinimide (NHS) and 3-(4,5-dimethylthiazol-2-yl)-2,5diphenyltetrazolium bromide (MTT), abs. toluene, tripropylamine, p-toluenesulfonyl hydrazide, xylenes, BHT, 1,4dioxane, TFA, abs. THF, $\mathrm{LiAlH}_{4}$, abs. diethyl ether, $\mathrm{N}$ methylmorpholine $\mathrm{N}$-oxide, $\mathrm{OsO}_{4}, \quad \mathrm{n}$-hexane, 1,5cyclooctadiene, m-chloroperbenzoic acid, 1,6-heptadiene-4-ol, palladium on carbon, ethyl vinyl ether and fluorescein sodium salt were obtained from Sigma Aldrich, ruthenium catalyst G2 was from Materia Inc. Sorafenib (free base) was purchased from LC Laboratories (US). Cyanine 5 amine was the product of Lumiprobe Gmbh (Germany).

\section{Polymer preparation}

PVA-4 was synthetized (Fig. 3. a) by the ROMP of acetalsubstituted cyclooctene (COE), where acetal moiety worked as a protecting group for 5,6-dihydroxy-COE to increase the solubility of the polymer. Acetals were polymerized with G2 catalysts (Fig. 1. a). Saturation of the polymer backbone, followed by deprotection, generated perfectly alternating copolymers of vinyl alcohol and ethylene.(Scherman et al., 2005)

PVA-5 was synthetized (Fig. 3. b) by the ADMET of 1,6heptadien-4-ol(Tuba et al., 2014) and PVA-8 (Fig. 3. c) by the ROMP of cyclooct-4-en-1-ol(Martinez et al., 2014) with G2 catalyst (Fig. 1. a) in an open vial in a glovebox at ambient temperature. Hydrogenation of the resulting polymers were performed on palladium on carbon followed by atmospheric hydrogen exposure.(Tuba et al., 2014)

\section{Polymer characterization}

Routine ${ }^{1} \mathrm{H}$ NMR spectra were obtained on a Varian Unity INOVA spectrometer operating at an equivalent ${ }^{1} \mathrm{H}$ frequency of $500 \mathrm{MHz}$ performed at $30^{\circ} \mathrm{C}$.

The GPC system was composed of a Waters 515 HPLC pump, a Waters 717plus Autosampler, a column system of 2 Waters Styragel HR columns (HR1 and HR4), a Jetstream thermostat and an Agilent Infinity 1260 Differential Refractometer detector. Distilled tetrahydrofuran was used as eluent with a flow rate was $0.3 \mathrm{~mL} / \mathrm{min}$.

Thermogravimetric analyses were performed in air (50 ml/min) using a Perkin Elmer Pyris 1 Thermogravimetric Analyser over a temperature interval $30-600{ }^{\circ} \mathrm{C}$ at a heating rate of $10^{\circ} \mathrm{C} \mathrm{min}^{-1}$.

\section{PVA-fluorescein blend preparation}

$100 \mathrm{mg}$ of polymer was dissolved in $5 \mathrm{ml}$ of the appropriate solvent ( $\mathrm{H}_{2} \mathrm{O}-\mathrm{PVA}$, DMSO-PVA-4, MeOH-PVA-5, THF-PVA-8) and $5 \mathrm{mg}$ of fluorescein was separately dissolved in $3 \mathrm{ml}$ of methanol then the solutions were mixed and stirred together for an additional 20 minutes, then the solvent was removed by rotavapor. The sample was homogenized by mechanical mixing and $10 \mathrm{mg}$ of the resulting solid material was pressed into a tablet by direct compression with a PerkinElmer Manual Hydraulic Press (5 tons).

\section{PVA-sorafenib nanoparticle preparation}

The nanocomposites were formed by nanoprecipitation method. During the process $1 \mathrm{ml} 10 \mathrm{mg} / \mathrm{ml}$ PVA-5 polymer dissolved in ethanol and $0.1-0.2 \mathrm{ml} 10 \mathrm{mg} / \mathrm{ml}$ sorafenib solution in aceton were combined, and added (one-shot) to 10 $\mathrm{ml}$ aqueous solution containing PVA, Pluronic F68 or Tween 80 emulsifier. The organic solvent was evaporated by magnetic stirring overnight at room temperature and 1 bar. Blank PVA-5 nanoparticles were prepared similarly using Pluronic F68 emulsifier, though without sorafenib active agent. To prepare sorafenib crystals, the drug was precipitated by the same method, but without adding the encapsulating polymer. The nanocomposite dispersions were centrifuged by a Hermle Z216 MK microcentrifuge (Germany) with 15,000 rpm for $20 \mathrm{~min}$, washed and redispersed in equal volume of MilliQ water three times.

\section{Characterization of nanoparticles}

The nanocomposites were imaged with FEI Apreo scanning electron microscope (SEM, Thermofisher, USA) at $20 \mathrm{kV}$. The size distribution of the NPs was measured by dynamic light scattering method with a Zetasizer Nano ZS (Malvern Instruments, Malvern, UK). The particles were characterized by the intensity mean diameter and polydispersity index (PDI). Zeta potential was measured also by Zetasizer Nano ZS (Malvern Instruments, Malvern, UK) after washing and redispersion of the nanoparticles in MilliQ water. Thermal behavior of the samples was investigated by differential scanning calorimetry (DSC) on a Setaram LabsysEvo system. The measurements were performed in flowing $(50 \mathrm{~mL} / \mathrm{min})$ high purity argon (99.999\%) atmosphere, in $25-300{ }^{\circ} \mathrm{C}$ temperature range with a scanning rate of $10{ }^{\circ} \mathrm{C} / \mathrm{min}$. An average of 4-5 mg sample was placed into $100 \mu \mathrm{L}$ aluminium crucible. The measurement results were blank corrected. All measurement results were evaluated with Calisto Processing (v2.01) software.

The encapsulation efficiency was determined after dissolving $10 \%$ of the prepared and washed nanoparticles in 5 $\mathrm{ml}$ ethanol. The sorafenib concentration was measured by HPLC. The chromatography system was Young Lin YL 9100, YL Instruments Co., Ltd, South Korea. Chromatographic separation was performed on a Zorbax SB-Aq column (150 mm $\times 4.6 \mathrm{~mm}, 5 \mu \mathrm{m}$; Agilent, USA). The mobile phase from time zero till 5 min was composed of $70 \%$ distilled water $(0,025 \%$ tetrachloroacetic acid) and $30 \%$ methanol. The percentage of methanol was increased continuously to $100 \%$ over $22 \mathrm{~min}$, and remained till the time point $30 \mathrm{~min}$. Then, the composition was changed back to distilled water $(0,025 \%$ TFA)-methanol (70:30; v:v) within $5 \mathrm{~min}$. The flow rate was of $1 \mathrm{~mL} / \mathrm{min}$ throughout the 35-min run. Chromatography was performed at $30{ }^{\circ} \mathrm{C}$. The absorbance of eluent was measured at a wavelength of $255 \mathrm{~nm}$.

The concentration of sorafenib was calculated using a calibration curve and the encapsulation efficiency was calculated as follows:

Encapsulation efficiency $(\%)=$ (mass of drug in NP / mass of total loaded drug) $\times 100$. 


\section{In vitro drug release}

During the pre-programmed drug release experiments fluorescein as a model compound was embedded into polymers (PVA, PVA-4, PVA-5 and PVA-8) synthesized with different polarities, from which fluorescein release was monitored by Metertech SP-8001 UV/Visible Spectrophotometer at $490 \mathrm{~nm}$.(Doughty, 2010) The physiological condition was ensured by phosphate buffered saline aqueous solution $(50 \mathrm{ml})$ and incubation at $37{ }^{\circ} \mathrm{C}$, continuous shaking at $200 \mathrm{rpm}$. Samples were taken at the $0^{\text {th }}$, $5^{\text {th }}, 10^{\text {th }}, 20^{\text {th }}, 30^{\text {th }}$ minutes and $1^{\text {st }}, 2^{\text {nd }}, 4^{\text {th }}, 6^{\text {th }}$ hours of the experiments. In each case, the experiments were repeated at least three times, the standard deviation of the results was well within $10 \%$.

The sorafenib-loaded nanocomposite was subjected to biorelevant in vitro drug release experiments, that is, after their washing, $10 \mathrm{mg}$ nanocomposites were re-suspended in $15 \mathrm{ml}$ human blood plasma containing $0.03 \%$ sodium azide bactericide. The NPs in release medium were incubated at $37^{\circ} \mathrm{C}$ in $\mathrm{G} 24$ Environmental Incubator Shaker (New Brunswick Scientific Co. Inc., USA) and shaken by BIO RS-24 Mini-rotator (Biosan, Latvia) for 2 days at $700 \mathrm{rpm}$. At predetermined intervals, $0.5 \mathrm{ml}$ of each sample was centrifuged (Hermle Z216 MK microcentrifuge, Germany) for $20 \mathrm{~min}$ at 15,000 rpm, washed three times and the gained nanoparticles were dissolved in $0.5 \mathrm{ml}$ ethanol. The sorafenib concentration was analyzed after HPLC separation as described above.

\section{Fluorescent dye conjugation}

For cellular uptake studies the PVA-sorafenib nanoparticles were fluorescently labelled in order to make them visible for fluorescent activated cell sorting (FACS). Briefly, washed nanoparticle $(1 \mathrm{mg}$ ) dispersion that was resuspended in $0.5 \mathrm{ml}$ PBS (pH 7.4) was mixed with $0.1 \mathrm{ml}$ PBS (pH 7.4) containing 10 $\mathrm{mg}$ EDC and $10 \mathrm{mg} \mathrm{NHS}$, and incubated for $60 \mathrm{~min}$ at $25^{\circ} \mathrm{C}$, centrifuged and washed with MilliQ water, and redispersed in $1.0 \mathrm{ml}$ PBS ( $\mathrm{pH}$ 7.4). The prepared carbodiimide activated nanoparticle dispersion was added to $0.02 \mathrm{ml} \mathrm{PBS}(\mathrm{pH} 7.4)$ solution containing $0.5 \mathrm{mg} / \mathrm{ml}$ Cyanine 5 amine fluorescent dye, and incubated $1 \mathrm{~h}$ at $25^{\circ} \mathrm{C}$. Then, the suspension of nanoparticles was centrifuged, washed three times and redispersed in $1 \mathrm{ml}$ PBS.

\section{Cell cultures}

The human cancer cell line HT-29 was grown in RPMI-1640 medium including $10 \%$ fetal calf serum (FCS) and $100 \mathrm{U} / \mathrm{ml}$ penicillin. The cells were cultured at $37{ }^{\circ} \mathrm{C}$ in a humidified atmosphere containing $5 \% \quad \mathrm{CO}_{2}$. They were trypsinized, resuspended and precultured before use.

\section{In vitro cellular uptake and cytotoxicity studies}

HT-29 cellular uptake of the nanoparticles was investigated by FACS. The cells were cultured in 24 -well plates at a cell density of $2 \times 10^{5}$ cells per well at $37{ }^{\circ} \mathrm{C}$ for $24 \mathrm{~h}$. Then, $0.1 \mathrm{ml}$ suspension containing 100 ?]g fluorescently labelled nanoparticle was added to each well ( 3 parallel) and incubated for $24 \mathrm{~h}$. The cells cultivated without the nanoparticles were used as negative control. The cells were washed by PBS, trypsinized and redispersed in PBS containing 2\% BSA. Flow cytometry was done by a BD FACSAria III Cell sorter (BD Biosciences, San Jose, CA, US) at Ex/Em 633/660 nm wavelength. Shortly, fluorescent light is emitted by fluorescent molecules after excitation by a laser of suitable wavelength. Fluorescent light may originate from naturally fluorescing materials in the cell, or may originate from fluorescent dyes used to label the cell. Using FACS one can physically sort a heterogeneous mixture of cells into different populations. Usual representation includes the intensity of a single channel (horizontal axis) vs number of detected events (vertical axis). Histograms can be used to compare a single parameter from two different sample populations (e.g. experimental vs. control). (see in detail https://www.antibodiesonline.com/resources/17/1247/what-is-flow-cytometry-facsanalysis/)

MTT cytotoxicity assay based on a colorimetric reaction was applied to study the effect on viability of HT-29 carcinoma cells. Cells were seeded (10000 cells/well) in 96-well plates. After $24 \mathrm{~h}$ pre-incubation, $200 \mu \mathrm{l}$ fresh RPMI-1640 medium containing $10 \%$ FCS and $50 \mu$ P PVA-sorafenib nanoparticles were pipetted to each well ( 8 parallel). The effect of four sorafenib concentration levels $(0.5 \mu \mathrm{g}, 1.0 \mu \mathrm{g}, 2.5 \mu \mathrm{g}$ and 5.0 $\mu \mathrm{g}$ per well). The positive control samples were also supplied by the same amount of free sorafenib in DMSO solution. DMSO cytotoxicity (without drugs) was also investigated. After $12 \mathrm{~h}, 24 \mathrm{~h}$ and $48 \mathrm{~h}$ incubation $20 \mu \mathrm{l} /$ well MTT solution $(5 \mathrm{mg}$ $\mathrm{MTT} / \mathrm{ml}$ ) and $0.2 \mathrm{ml} /$ well culture media were added and the incubation took $2 \mathrm{~h}$. The supernatant was removed, and MTT lysis solution (DMSO, 1\% acetic acid, 10\% SDS) was pipetted into each well. The cells containing the formed MTT formazan crystals were dissolved during $30 \mathrm{~min}$, and, the absorbance of cell suspension was measured at $492 \mathrm{~nm}$ by a plate reader (Robonik Readwell Touch, India). The viability of treated cells was related to that of the untreated cells (negative control).

\section{Results and discussion}

In vitro fluorescein release of PVA blends. Preliminary PVAfluorescein composite release tests were performed using commercially available PVA. These experiments were used as etalon tests for the comparison of the fluorescein release properties of composites made from polymers with preadjusted polarity (various $\mathrm{C} / \mathrm{OH}$ ratios).

Fig. 4 shows clearly that polymers with different polarity can affect controlled fluorescein release. From the water-soluble PVA rapid fluorescein release was observed, as the embedded compound was completely dissolved within the first 20 minutes of the reaction. The experiences demonstrated that the greater the $\mathrm{C} / \mathrm{OH}$ ratio is in the polymer, the slower the release of the drug. After 6 hours, the release of the fluorescein was only $67 \%, 51 \%$ and $30 \%$ for the poly(vinyl alcohol alt-ethylene) (PVA-4), poly(vinyl alcohol altpropenylene) (PVA-5) and poly(vinyl alcohol alt-hexenylene) (PVA-8), respectively.

\section{Insert Figure 4 here}

Considering the model drug release experiments, the most promising sparingly water-soluble polymer, PVA-5 was selected for further investigations. On Fig. 5 the rate of fluorescein release is shown in a 6-day time interval. A 
relatively intense fluorescein release was observed on the first day of the experiment, it reached about $65 \%$. However, the process has slowed down and reached only about $85 \%$ for the $6^{\text {th }}$ day of the experiment with the standard deviation of the results within $10 \%$.

Insert Figure 5 here

Physical and chemical properties of PVA-sorafenib nanoparticles. PVA-5 and PVA-8 were evaluated as having the most favourable release kinetics with the model drug, they were examined, whether they are suitable for encapsulating sorafenib anticancer drug. Meanwhile the PVA-8 showed highly non-polar characteristics and was hardly soluble in most general solvents, the PVA-5 exhibited sparing solubility in water and good solubility in ethanol. In fact, PVA-8 was soluble exclusively in hot tetrahydrofuran, and after nanoprecipitation in the presence of different emulsifiers, nanoparticles could not be prepared, a huge agglomerate formation was observed. Hence, PVA-5 was selected to prepare nanotherapeutics by nanoprecipitation method (Miladi et al., 2016). Three different emulsifiers PVA, Tween 80 and Pluronic F68 were investigated during the preparation process. Tween 80 emulsifier in the nanoprecipitation process provided nanocomposites with large size, while the use of PVA surface active agent resulted in submicronsized nanoparticles. Pluronic F68 provided the smallest nanocomposites (Fig. 6), thus, it was used to optimize the particle preparation.

\section{Insert Figure 6 here}

Pluronic F68 concentration was varied in the range of $0.5-5.0 \%$ in the water phase to find out the optimal emulsifier concentration. However, a minimum in the size was found at a surfactant concentration of $2 \%$ (see Fig. 7 and Table 2) but a small peak in the micron size range can be seen in the size distribution (Fig. 7). This is also reflected in the PDI value (Table 2 ) that is higher than 0.2 , which can be attributed to the agglomeration of the nanoparticles or separately precipitated sorafenib particles. The multimodal distribution of PVA-5-sorafenib prepared using 5\% Pluronic F68 emulsifier might result from the micelle formation beside the mentioned reasons.

According to Fig. 7 and Table 2 it can be established that $1 \%$ Pluronic F68 concentration is optimal for the nanocomposite preparation in this process. Nanoparticle morphology was monitored by scanning electron microscope (SEM) indicating the formation of particles mostly of submicron size. This is in accordance with the results of measurements achieved by dynamic light scattering method.

Insert Figure 7 here

\begin{tabular}{cccc}
\hline $\begin{array}{c}\text { Emulsifier } \\
\text { concentration (\%) }\end{array}$ & $\begin{array}{c}\text { Intensity mean } \\
\text { size (d.nm) }\end{array}$ & PDI & $\begin{array}{c}\text { Zeta potential } \\
(\mathbf{m V})\end{array}$ \\
\hline 0.5 & 306.1 & 0.179 & -0.18
\end{tabular}

\begin{tabular}{llll}
1 & 271.2 & 0.142 & -0.45 \\
2 & 225.2 & 0.216 & -0.53 \\
5 & 430.0 & 0.376 & -0.92 \\
\hline
\end{tabular}

Table 2 Intensity mean diameter, PDI and zeta potential values of PVA-5-sorafenib nanoparticles as a function of Pluronic F68 concentration.

Interestingly, most of the particles exhibited cubic shape (Fig. 8. a) which is rather unusual among the polymeric nanoparticles.(El-Enin and AL-Shanbari, 2018; Karami and Hamidi, 2016; Salah et al., 2017) The precipitation of sorafenib also produced cubic crystals (Fig. 8. b), although their size was considerably larger, with an average diameter of $1.45 \mu \mathrm{m}$, while composites containing both the polymer and sorafenib had optimally an average size of 225-271 nm (Table 2). It means the polymeric nanocomposites also followed the shape of the sorafenib crystals, however with substantially reduced size.

\section{Insert Figure 8 here}

Differential scanning calorimetry (DSC) investigation has been done in order to confirm the SEM results. Fig. 9 draws the DSC curves of pure-, precipitated sorafenib and PVA-5-sorafenib nanocomposite. The endothermic peaks found in all of the three thermograms clearly suggest crystal structure of each sample. Pure sorafenib and precipitated sorafenib had very similar thermograms, as expected. The two overlapping peaks show two different polymorphs: a more stable with a high and narrow endotherm and a less stable with a wide one. These peaks can be observed also in the PVA-5-sorafenib nanocomposite, however, with a substantial shift that verifies the formation of nanocrystals, which are visible also in the SEM image (Fig. 8).

\section{Insert Figure 9 here}

The encapsulation efficiency reached its maximum at $2 \%$ Pluronic F68 concentration (Table 3), and because the yield of the nanoparticles did not change significantly by increasing the emulsifier concentration, the loading degree was also the highest $(12.0 \%)$ at this concentration of surfactant. The ratio of encapsulated active agent reduced significantly, when the emulsifier concentration was increased to $5 \%$, which can be explained by the elevated solubility of the sorafenib due to the high emulsifier concentration. Zeta potential value of PVA-5-sorafenib nanoparticles in MilliQ water determined by Zetasizer (Malvern Instruments, UK) did not show stabilization by charge of the nanoparticles (Table 2). However, the nanoparticle suspensions did not show aggregation in the solution of emulsifier during a day or in blood plasma during the release study.

\begin{tabular}{cccc}
\hline $\begin{array}{c}\text { Emulsifier } \\
\text { concentration (\%) }\end{array}$ & $\begin{array}{c}\text { Encapsulation } \\
\text { efficiency (\%) }\end{array}$ & Yield (\%) & Loading degree (\%) \\
\hline 0.5 & 52.2 & 70.4 & 6.8 \\
1 & 82.1 & 69.4 & 10.7 \\
2 & 93.6 & 71.1 & 12.0
\end{tabular}


Table 3 Encapsulation efficiency, yield and loading degree values of PVA-sorafenib nanoparticles as a function of Pluronic F68 concentration.

Biorelevant drug release of PVA-5-sorafenib nanoparticles. Sorafenib release of the prepared nanocomposites was investigated under biorelevant condition in human blood plasma. The active agent was released from the nanocomposites continuously within one day (Fig.10.). This is substantially quicker, than that was found for fluorescein. Nevertheless, the nanocomposites possess significantly higher surface area compared to the PVA blends Moreover, the plasma release medium contains a lot of protein that can behave as surfactant, thus via the solubilisation they can accelerate the dissolution of sorafenib. Nevertheless, serum proteins were proved to be prone to interact with sorafenib.(Shi et al., 2015)

Insert Figure 10 here

Carcinoma cellular uptake and cytotoxicity of PVA-5-sorafenib nanoparticles. In cellular uptake studies by HT-29 model carcinoma cells, during the $24 \mathrm{~h}$ incubation time, all of the cells engulfed fluorescently labelled sorafenib loaded PVA-5 nanoparticles (Fig. 11) with a relative count of $16690 \pm 1401$. Fig. 10 shows the histograms of control cells (A) and cells cured with fluorescent labelled PVA-5-sorafenib nanoparticles. Comparing the two histograms, it can be seen that there is not any overlap between the peaks, which means all of the cells contained the fluorescent dye after incubation with the labelled nanoparticles.

\section{Insert Figure 11 here}

Cytotoxicity tests were performed on HT-29 cells using different active agent concentrations. Sorafenib solution was added to the cells in DMSO solution, thus the effect of the same concentration ( $0.5 \%$ related to the medium volume) of DMSO was also investigated and it did not exert significant toxic effect.

Blank PVA-5 nanoparticles without active agent neither decreased the viability of the cells compared to the non-treated cells (negative control) (Figure 12). As expected, sorafenib solution triggered concentration-dependent cytotoxicity and this was also observed by the nanocomposites. However, the viability was reduced to a smaller extent, probably due to the prolonged release of the drug. $48 \mathrm{~h}$ incubation with the nanocomposites resulted in the highest cytotoxic effect. Although all of the drug was released within one day, the burst effect was not too high. Thus, the available drug concentration is substantially lower for some hours than in the case of sorafenib solution. The rate of cellular uptake must have also influenced the cytotoxicity of the nanoparticles.

Insert Figure 12 here
Well-defined vinyl alcohol (VA) copolymer carriers with finetuneable polarity were synthesized via olefin metathesis reactions by ROMP and ADMET. By fine tuning the number of hydroxyl groups on the polymer chain enabled preprogrammed drug release of the embedded model drug, fluorescein. Most beneficial carrier copolymer, PVA-5 was used to incorporate sorafenib anticancer drug by nanoprecipitation resulting in the formation of unusual cubicshaped nanocomposites. The formed particles released the active agent continuously within $24 \mathrm{~h}$. In HT-29 cancer cells concentration-related cytotoxicity of the sorafenib-loaded nanoparticles was observed. The results can be associated with the sustained release of the drug. So far we have experienced the formation of cubic-shaped polymeric nanocomposites neither in our experiments nor in the literature. The main significance of this finding is that the encapsulating polymer followed the structure of the drug, which is quite unusual, since by polymeric microencapsulation typically amorphous composites can be formed. Shape is critical parameter influencing cellular uptake and/or the speed and site specific drug delivery from the nanoparticles. Preferential interaction with targeted proteins can be reached on proper shape selection of nanomaterials (Ankamwar, 2012). This interesting feature of the well-defined PVA polymer might be useful in some other application (e.g. diagnostic or optical), where the shape gets more role in the function of a composite. Thus, in the following studies it is important to clarify, whether this surprising phenomenon can be realized using this polymer in composite with other components.

\section{Acknowledgements}

This work was funded by grants provided by the National Competitiveness and Excellence Program, Hungary (NVKP_161-2016-0007) and by the BIONANO_GINOP-2.3.2-15-201600017 project. Dr. Tivadar Feczkó acknowledges the funding of Alexander von Humboldt Foundation (Ref. No.: 3.3UNG/1161203 STP and 3.3-1161203-HUN-HFST-E) and the support of Hungarian Academy of Sciences via Bilateral Joint Project with the Polish Academy of Sciences.

\section{Conflicts of interest}

There are no conflicts to declare.

\section{Notes and references}

Ankamwar, B., 2012. Size and Shape Effect on Biomedical Applications of Nanomaterials. In: Hudak, R., Penhaker, M., Majerni, J. (eds) Biomedical Engineering - Technical Applications in Medicine. IntechOpen Ltd. https://doi.org/10.5772/46121

Balla, Á., Al-Hashimi, M., Hlil, A., Bazzi, H.S., Tuba, R., 2016. Ruthenium-Catalyzed Metathesis of Conjugated Polyenes. ChemCatChem 8, 2865-2875. https://doi.org/10.1002/cctc.201600479

\section{Conclusions}

Chandra, R., Rustgi, R., 1998. Pergamon BIODEGRADABLE 
POLYMERS. Prog. Polym. Sci. 23, 1273-1335.

https://doi.org/10.1016/S0079-6700(97)00039-7

Chiellini, E., Corti, A., D'Antone, S., Solaro, R., 2003. Biodegradation of poly (vinyl alcohol) based materials, Progress in Polymer Science (Oxford). https://doi.org/10.1016/S00796700(02)00149-1

Doughty, M.J., 2010. PH dependent spectral properties of sodium fluorescein ophthalmic solutions revisited. Ophthalmic Physiol. Opt. 30, 167-174. https://doi.org/10.1111/j.14751313.2009.00703.x

El-Enin, H.A., AL-Shanbari, A.H., 2018. Nanostructured liquid crystalline formulation as a remarkable new drug delivery system of anti-epileptic drugs for treating children patients. Saudi Pharm. J. https://doi.org/10.1016/j.jsps.2018.04.004

Gan, Y., Bai, S., Hu, S., Zhao, X., Li, Y., 2016. Reaction mechanism of thermally-induced electric conduction of poly(vinyl alcohol)silver nitrate hybrid films. RSC Adv. 6, 56728-56737. https://doi.org/10.1039/c6ra08994a

George, J., Sajeevkumar, V.A., Ramana, K.V., Sabapathy, S.N., Siddaramaiah, 2012. Augmented properties of PVA hybrid nanocomposites containing cellulose nanocrystals and silver nanoparticles. J. Mater. Chem. 22, 22433-22439. https://doi.org/10.1039/c2jm35235d

Ghori, M.U., Conway, B.R., 2015. Hydrophilic Matrices for Oral Control Drug Delivery. Am. J. Pharmacol. Sci. 3, 103-109. https://doi.org/10.12691/AJPS-3-5-1

Hillmyer, M.A., Laredo, W.R., Grubbs, R.H., 1995. Ring-Opening Metathesis Polymerization of Functionalized Cyclooctenes by a Ruthenium-Based Metathesis Catalyst. Macromolecules 28, 6311-6316. https://doi.org/10.1021/ma00122a043

Hsu, M.H., Hsu, S.M., Kuo, Y.C., Liu, C.Y., Hsieh, C.Y., Twu, Y.C., Wang, C.K., Wang, Y.H., Liao, Y.J., 2017. Treatment with lowdose sorafenib in combination with a novel benzimidazole derivative bearing a pyrolidine side chain provides synergistic anti-proliferative effects against human liver cancer. RSC Adv. 7, 16253-16263. https://doi.org/10.1039/c6ra28281d

Ito, S., Munakata, K., Nakamura, A., Nozaki, K., 2009. Copolymerization of vinyl acetate with ethylene by palladium/ alkylphosphine-sulfonate catalysts. J. Am. Chem. Soc. 131, 14606-14607. https://doi.org/10.1021/ja9050839

Karami, Z., Hamidi, M., 2016. Cubosomes: Remarkable drug delivery potential. Drug Discov. Today 21, 789-801. https://doi.org/10.1016/j.drudis.2016.01.004

Li, Z.L., Lv, A., Li, L., Deng, X.X., Zhang, L.J., Du, F.S., Li, Z.C., 2013. Periodic ethylene-vinyl alcohol copolymers via ADMET polymerization: Synthesis, characterization, and thermal property. Polym. (United Kingdom) 54, 3841-3849. https://doi.org/10.1016/j.polymer.2013.05.037

Long, F., Dong, C., Jiang, K., Xu, Y., Chi, X., Sun, D., Liang, R., Gao, Z., Shao, S., Wang, L., 2017. Melatonin enhances the anti-tumor effect of sorafenib via AKT/p27-mediated cell cycle arrest in hepatocarcinoma cell lines. RSC Adv. 7, 21342-21351. https://doi.org/10.1039/C7RA02113E

Mahanta, N., Valiyaveettil, S., 2012. In situ preparation of silver nanoparticles on biocompatible methacrylated poly(vinyl alcohol) and cellulose based polymeric nanofibers. RSC Adv. 2, 11389-11396. https://doi.org/10.1039/c2ra20637d

Malarvizhi, G.L., Retnakumari, A.P., Nair, S., Koyakutty, M., 2014.
Transferrin targeted core-shell nanomedicine for combinatorial delivery of doxorubicin and sorafenib against hepatocellular carcinoma. Nanomedicine Nanotechnology, Biol. Med. 10, 1649-1659.

https://doi.org/10.1016/j.nano.2014.05.011

Manasco, J.L., Tang, C., Burns, N.A., Saquing, C.D., Khan, S.A., 2014. Rapidly dissolving poly(vinyl alcohol)/cyclodextrin electrospun nanofibrous membranes. RSC Adv. 4, 1327413279. https://doi.org/10.1039/c3ra43836h

Martinez, H., Ren, N., Matta, M.E., Hillmyer, M.A., 2014a. Ringopening metathesis polymerization of 8-membered cyclic olefins. Polym. Chem. 5, 3507. https://doi.org/10.1039/c3py01787g

Martinez, H., Ren, N., Matta, M.E., Hillmyer, M.A., 2014b. Ringopening metathesis polymerization of 8-membered cyclic olefins. Polym. Chem. 5, 3507-3532. https://doi.org/10.1039/c3py01787g

Miladi, K., Sfar, S., Fessi, H., Elaissari, A. 2016 Nanoprecipitation Process: From Particle Preparation to In Vivo Applications. In: Vauthier C., Ponchel G. (eds) Polymer Nanoparticles for Nanomedicines. Springer, Cham. https://doi.org/10.1007/978-3-319-41421-8_2

Mori, Y., Sumi, H., Hirabayashi, T., Inai, Y., Yokota, K., 1994. Synthesis of Sequence-Ordered Copolymers. 4. Glass Transition and Melting Temperatures of Sequence-Ordered and Unordered Ethylene-Vinyl Alcohol and Ethylene-Vinyl Acetate Copolymers. Macromolecules 27, 1051-1056. https://doi.org/10.1021/ma00082a026

Okaya, T., 1993. Regulation in free-radical polymerization of vinyl acetate and synthesis of end-group modified poly(viny1 alcoho1)s 173, 163-173.

Pajak, J., Ziemski, M., Nowak, B., 2010. Poly(vinyl alcohol) biodegradable vinyl material. Chemik 64, 523-530.

Park, K., 2014. Controlled drug delivery systems: Past forward and future back. J. Control. Release 190, 3-8. https://doi.org/10.1016/j.jconrel.2014.03.054

Prakasam, M., Locs, J., Salma-Ancane, K., Loca, D., Largeteau, A., Berzina-Cimdina, L., 2017. Biodegradable Materials and Metallic Implants-A Review. J. Funct. Biomater. 8, 44. https://doi.org/10.3390/jfb8040044

Rajabi-Siahboomi, A.R., Bowtell, R.W., Mansfield, P., Davies, M.C., Melia, C.D., 1996. Structure and behavior in hydrophilic matrix sustained release dosage forms: 4 . Studies of water mobility and diffusion coefficients in the gel layer of HPMC tablets using NMR imaging. Pharm. Res. https://doi.org/10.1023/A:1016084224084

Sakai, S., Tsumura, M., Inoue, M., Koga, Y., Fukano, K., Taya, M., 2013. Polyvinyl alcohol-based hydrogel dressing gellable on wound via co- enzymatic reaction triggered by glucose in the wound exudate Shinji. Page 114 J. Mater. Chem. B 1, 50675075. https://doi.org/10.1039/b000000x

Salah, S., Mahmoud, A.A., Kamel, A.O., 2017. Etodolac transdermal cubosomes for the treatment of rheumatoid arthritis: Ex vivo permeation and in vivo pharmacokinetic studies. Drug Deliv. 24, 846-856. https://doi.org/10.1080/10717544.2017.1326539 
Santos, A.C., Caldas, M., Pattekari, P., Fontes Ribeiro, C., Ribeiro, A.J., Lvov, Y., Veiga, F., 2018. Layer-by-Layer coated drug-core nanoparticles as versatile delivery platforms, Design and Development of New Nanocarriers. https://doi.org/10.1016/B978-0-12-813627-0.00016-8

Sarkar, N., Walker, L.C., 1995. Hydration-dehydration properties of methylcellulose and hydroxypropylmethylcellulose. Carbohydr. Polym. 27, 177-185. https://doi.org/10.1016/0144-8617(95)00061-B

Scherman, O.A., Kim, H.M., Grubbs, R.H., 2002. Synthesis of WellDefined Poly (( vinyl alcohol ) 2 -alt-methylene ) via RingOpening Metathesis Polymerization. Macromoleculars 53665371. https://doi.org/10.1021/ma011901a

Scherman, O.A., Walker, R., Grubbs, R.H., 2005. Synthesis and characterization of stereoregular ethylene-vinyl alcohol copolymers made by ring-opening metathesis polymerization. Macromolecules 38, 9009-9014. https://doi.org/10.1021/ma0506861

Shi, J.H., Chen, J., Wang, J., Zhu, Y.Y., Wang, Q., 2015. Binding interaction of sorafenib with bovine serum albumin: Spectroscopic methodologies and molecular docking. Spectrochim. Acta - Part A Mol. Biomol. Spectrosc. 149, 630637. https://doi.org/10.1016/j.saa.2015.04.034

Stampella, A., Papi, A., Rizzitelli, G., Costantini, M., Colosi, C., Barbetta, A., Massimi, M., Devirgiliis, L.C., Dentini, M., 2013. Synthesis and Characterization of a Novel Poly(vinyl alcohol) 3D Platform for the Evaluation of Hepatocytes Response to Drug Administration. J. Mater. Chem. B 1, 3083-3098. https://doi.org/10.1039/c4tb00267a

Su, W.-F., 2013. Principles of Polymer Design and Synthesis. https://doi.org/10.1007/978-3-642-38730-2

Sutthasupa, S., Shiotsuki, M., Sanda, F., 2010. Recent advances in ring-opening metathesis polymerization, and application to synthesis of functional materials. Polym. J. 42, 905-915. https://doi.org/10.1038/pj.2010.94

Tom, G., Philip, S., Isaac, R., Praseetha, P.K., Jiji, S.G., Asha, V.V., 2018. Preparation of an efficient and safe polymericmagnetic nanoparticle delivery system for sorafenib in hepatocellular carcinoma. Life Sci. 206, 10-21. https://doi.org/10.1016/j.Ifs.2018.04.046

Tuba, R., Al-Hashimi, M., Bazzi, H.S., Grubbs, R.H., 2014. One-pot synthesis of poly(vinyl alcohol) (PVA) copolymers via ruthenium catalyzed equilibrium ring-opening metathesis polymerization of hydroxyl functionalized cyclopentene. Macromolecules 47, 8190-8195. https://doi.org/10.1021/ma501976v

Tuba, R., Balogh, J., Hlil, A., Barłóg, M., Al-Hashimi, M., Bazzi, H.S., 2016. Synthesis of recyclable tire additives via equilibrium ring-opening metathesis polymerization. ACS Sustain. Chem. Eng. 4, 6090-6094. https://doi.org/10.1021/acssuschemeng.6b01496

Uskoković, V., 2015. When $1+1>2$ : Nanostructured composites for hard tissue engineering applications. Mater. Sci. Eng. C 57, 434-451. https://doi.org/10.1016/j.msec.2015.07.050

Uskoković, V., Ghosh, S., 2016. Carriers for the tunable release of therapeutics: etymological classification and examples.

Expert Opin. Drug Deliv. 13, 1729-1741.

https://doi.org/10.1080/17425247.2016.1200558
Valenti, D.J., Wagener, K.B., 1998. Direct synthesis of well-defined alcohol-functionalized polymers via acyclic diene metathesis (ADMET) polymerization. Macromolecules 31, 2764-2773. https://doi.org/10.1021/ma9714833

Wagener, K.B., Boncella, J.M., Smith, W., 2006. Processes by Homogeneous Catalysis. https://doi.org/10.1002/0470862106.ia141

https://www.antibodies-online.com/resources/17/1247/whatis-flow-cytometry-facs-analysis/ 


\section{Graphical Abstract}

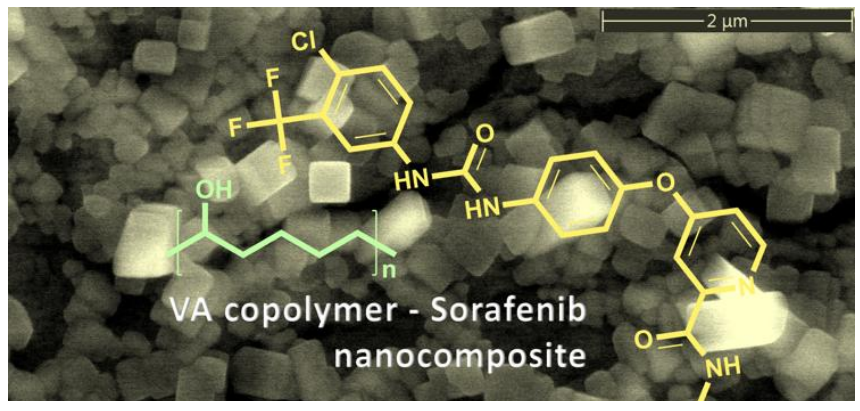

Sorafenib chemotherapeutic drug VAcopolymer $(\mathrm{C} / \mathrm{OH}=5$ ratio) nanocomposite exhibiting unusual cubic shape shows prolonged active agent release. 
Fig. 1 Structure of fluorescein model (drug compound - a), sorafenib (anticancer drug - b), GII catalyst (ruthenium-based metathesis catalyst - c).

Fig. 2 A generalized example of ring opening metathesis polymerization (ROMP - a) and acyclic diene metathesis polymerization (ADMET - b) reactions.

Fig. 3 Synthesis of well-defined VA-copolymers with different polarities (PVA-4, PVA-5 and PVA-8).

Fig. 4 Rate of fluorescein release from PVA blends as a function of carriers possessing different $\mathrm{C} / \mathrm{O}$ ratio.

Fig. 5 Rate of fluorescein release by PVA-5 blend (3 independent experiments) in a 6-day time interval.

Fig. 6 Size distribution of PVA-5-sorafenib nanoparticles prepared by PVA, Tween 80 or Pluronic F68 emulsifiers.

Fig. 7 Size distribution of PVA-5-sorafenib nanoparticles prepared by varying concentrations (0.5\% - blue line, $1.0 \%$ - yellow dashed line, $2.0 \%$ - green line, $5.0 \%$ - red line) of Pluronic F68 emulsifier.

Fig. 8 Scanning electron microscopic image of PVA-5-sorafenib nanoparticles (A) and precipitated sorafenib crystals (B).

Fig. 9 Differential scanning calorimetry thermograms of pure sorafenib (Sorafenib, green line), precipitated sorafenib (SOR-BLANK, red line) and PVA-5-sorafenib nanocomposite (SOR-18, blue line).

Fig. 10 Cumulative sorafenib release of the PVA-5-sorafenib nanocomposites in human blood plasma.

Fig. 11 Fluorescence-activated cell sorting (FACS) diagram of control cells without treatment (A) and cells treated with Cyanine5-labelled PVA-5-sorafenib nanocomposites (B).

Fig. 12 Viability of HT-29 cells by MTT assay due to DMSO, sorafenib in solution ('SOR', brown columns) and PVA-5-sorafenib nanoparticles ('PVA-SOR', green columns) after $12 \mathrm{~h}$, $24 \mathrm{~h}$ and $48 \mathrm{~h}$ incubation related to the non-treated (negative control) cells. 
Figure 1

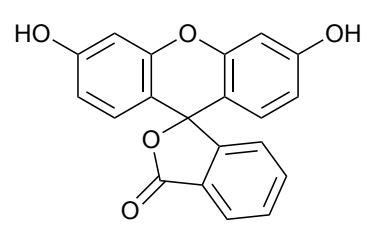

(a)

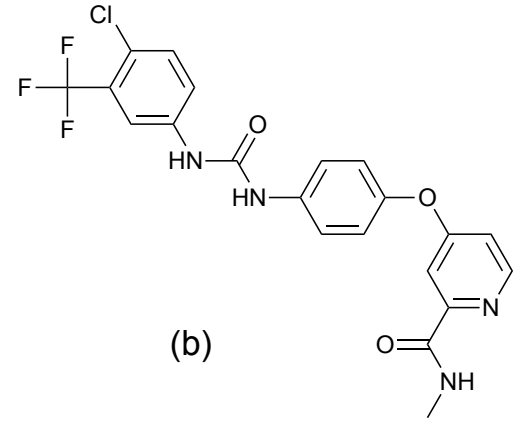

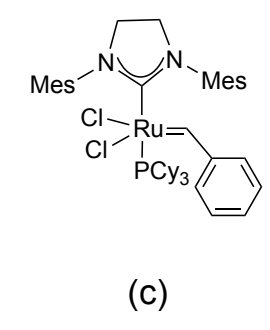

(c)

(a) (b)

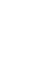


Figure 2

Figure 2 (b)

Figure 2 (a)

2

$\ldots$

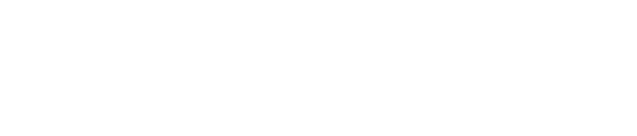$$
\text { . }
$$

.

.

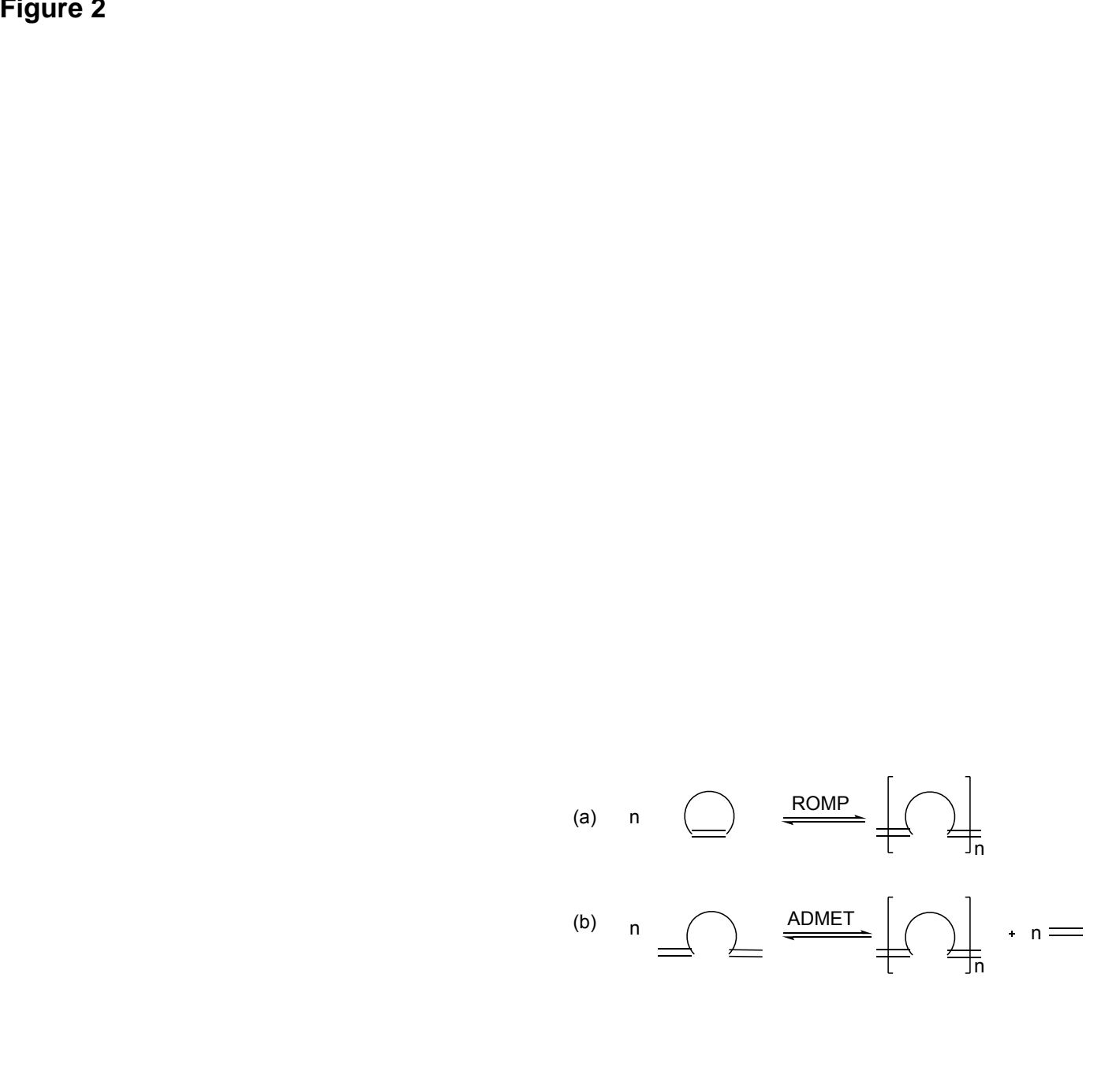




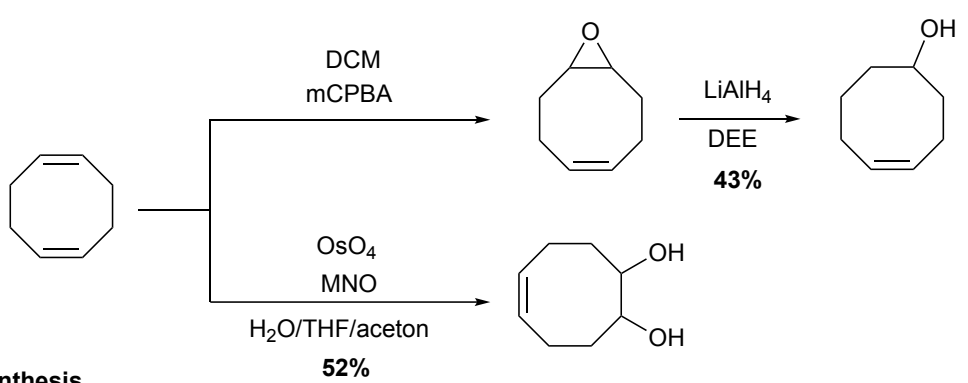

polymer synthesis

$52 \%$

(a)
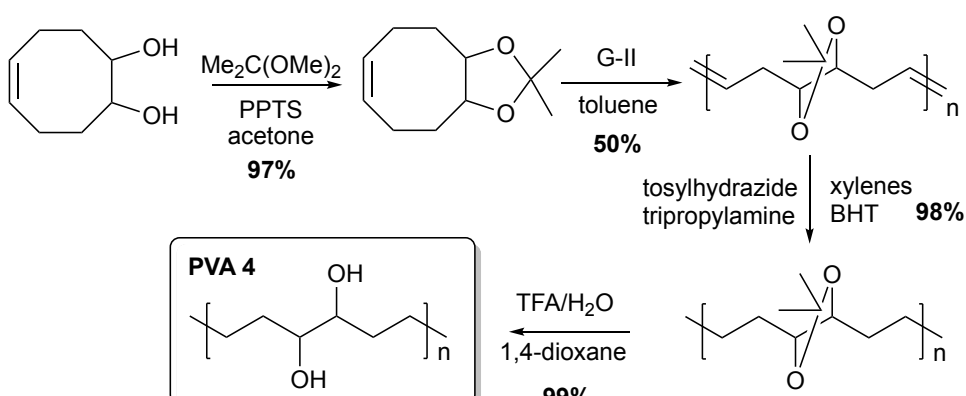

TFA/ $\mathrm{H}_{2} \mathrm{O}$

1,4-dioxane

$99 \%$

(b)

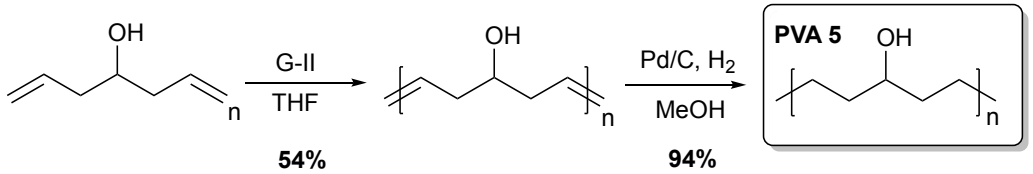

(c)

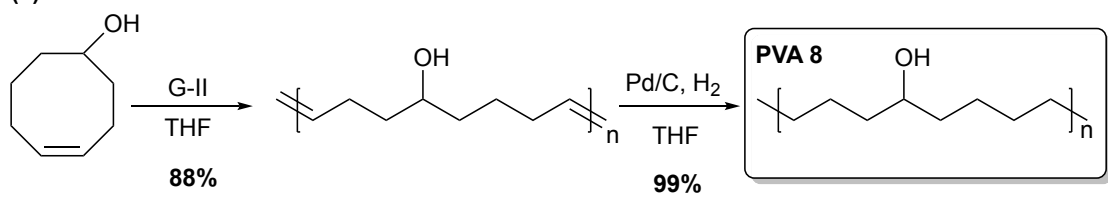




\section{Figure 4}

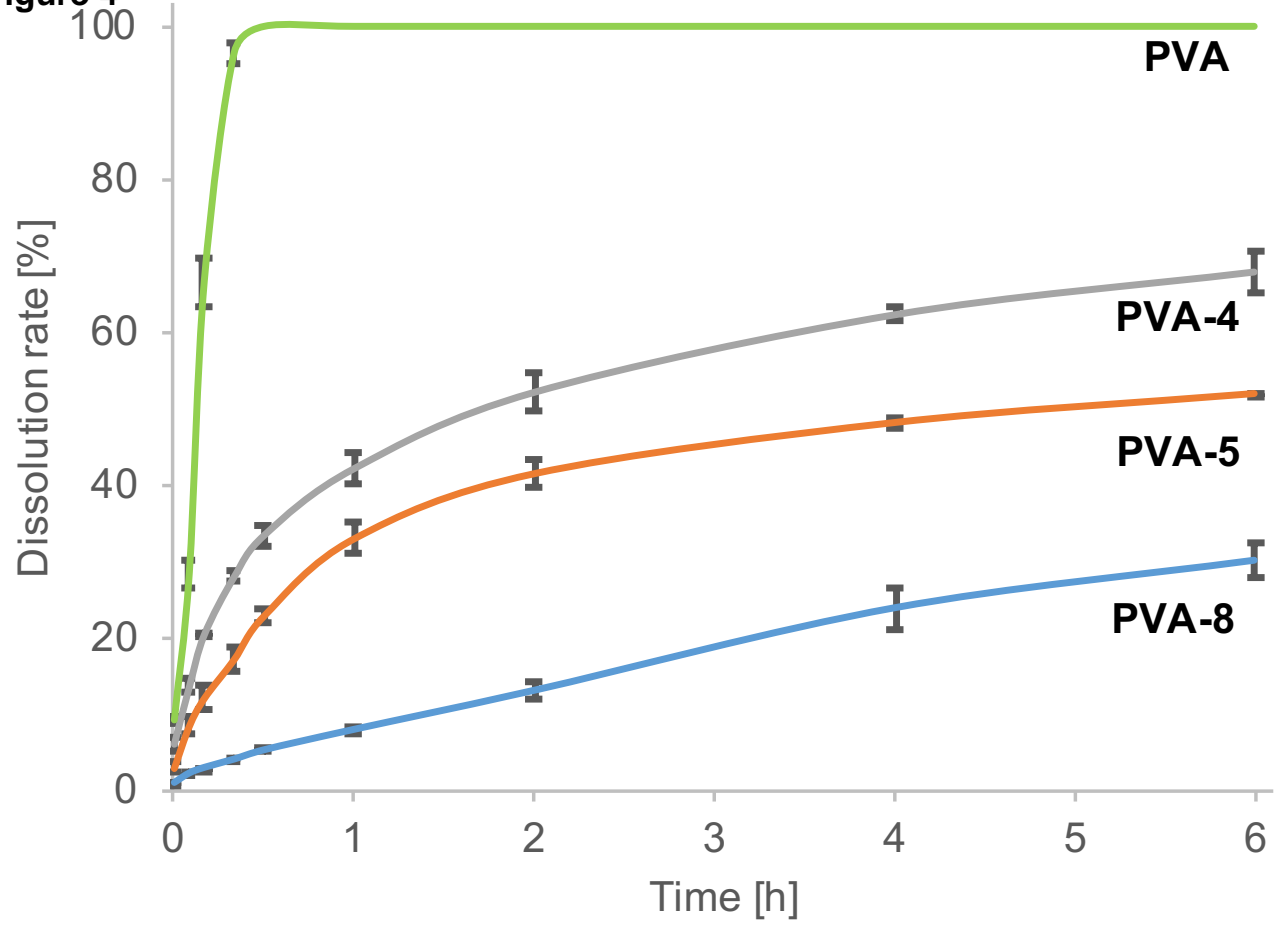




\section{Figure 50}

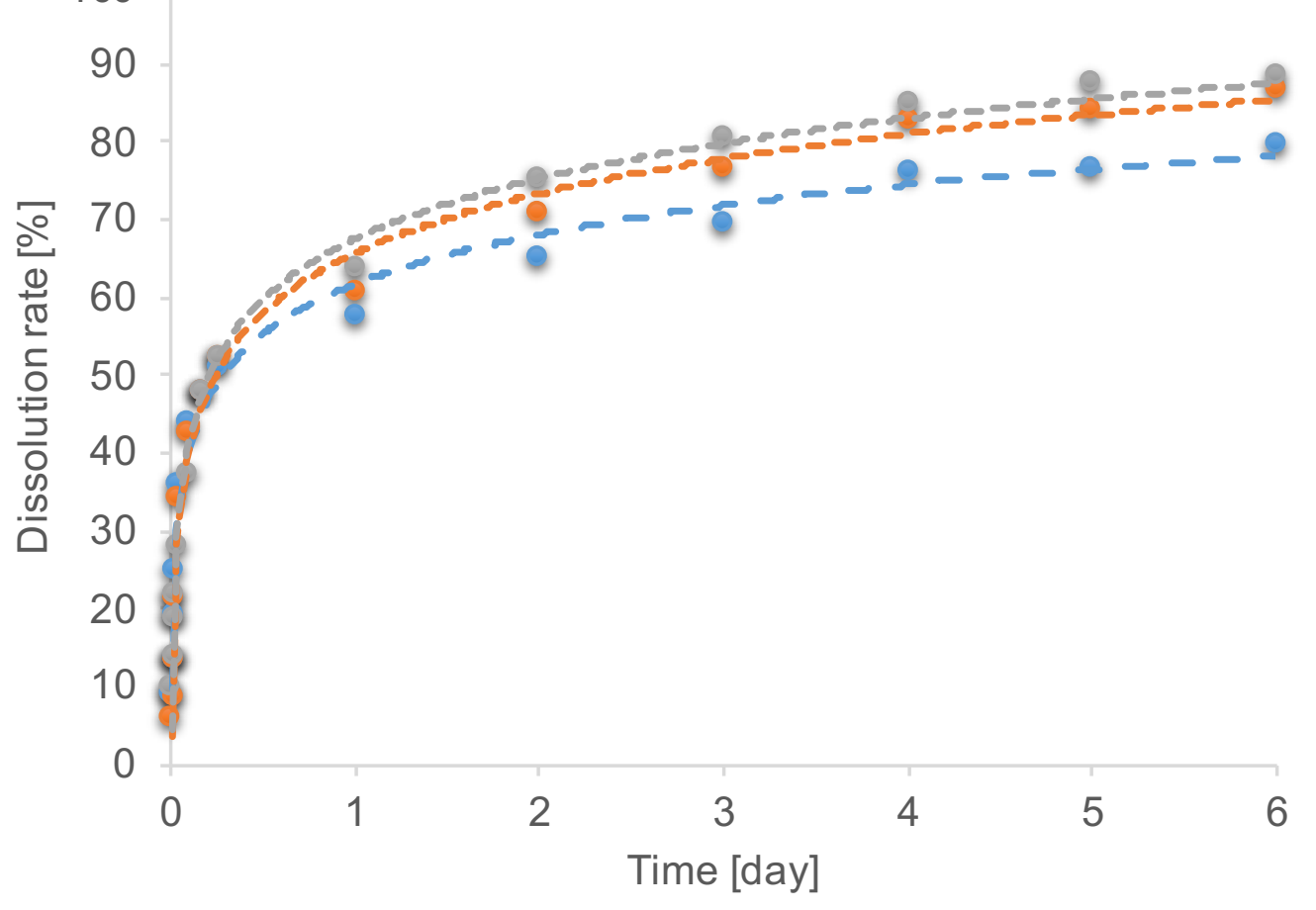




\section{Figure, 6}

-PVA -Tween $80 \quad$ Pluronic F68

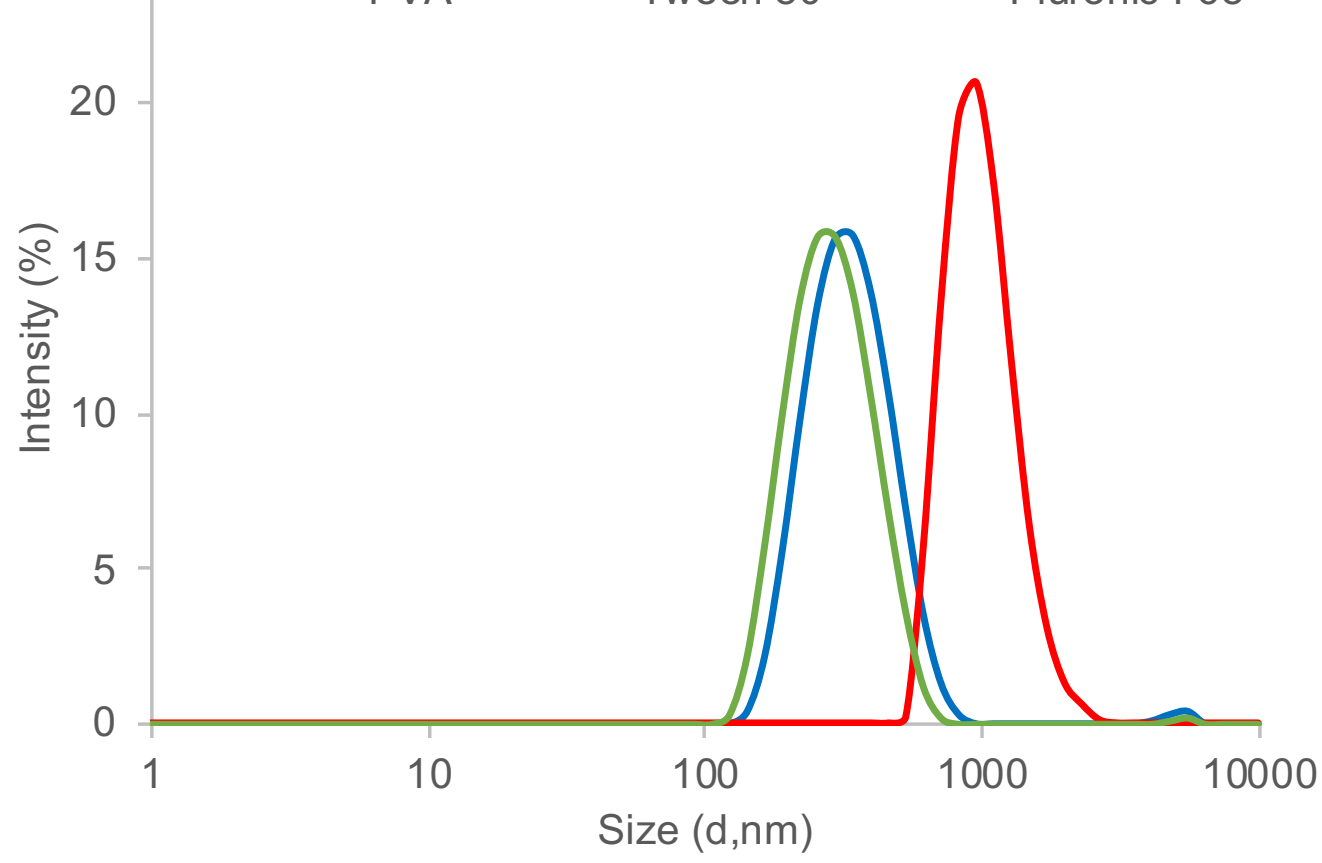


Figure 7

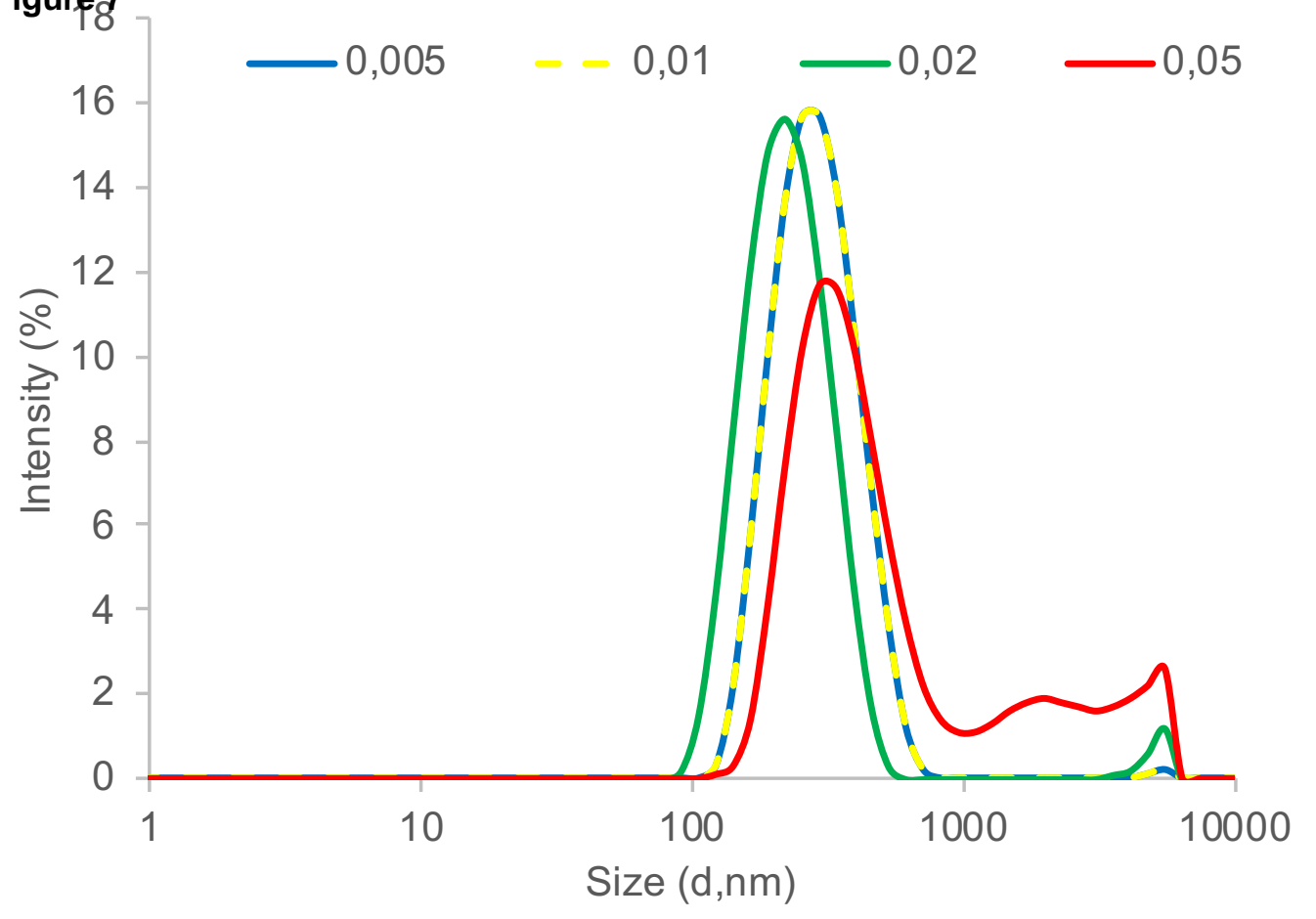




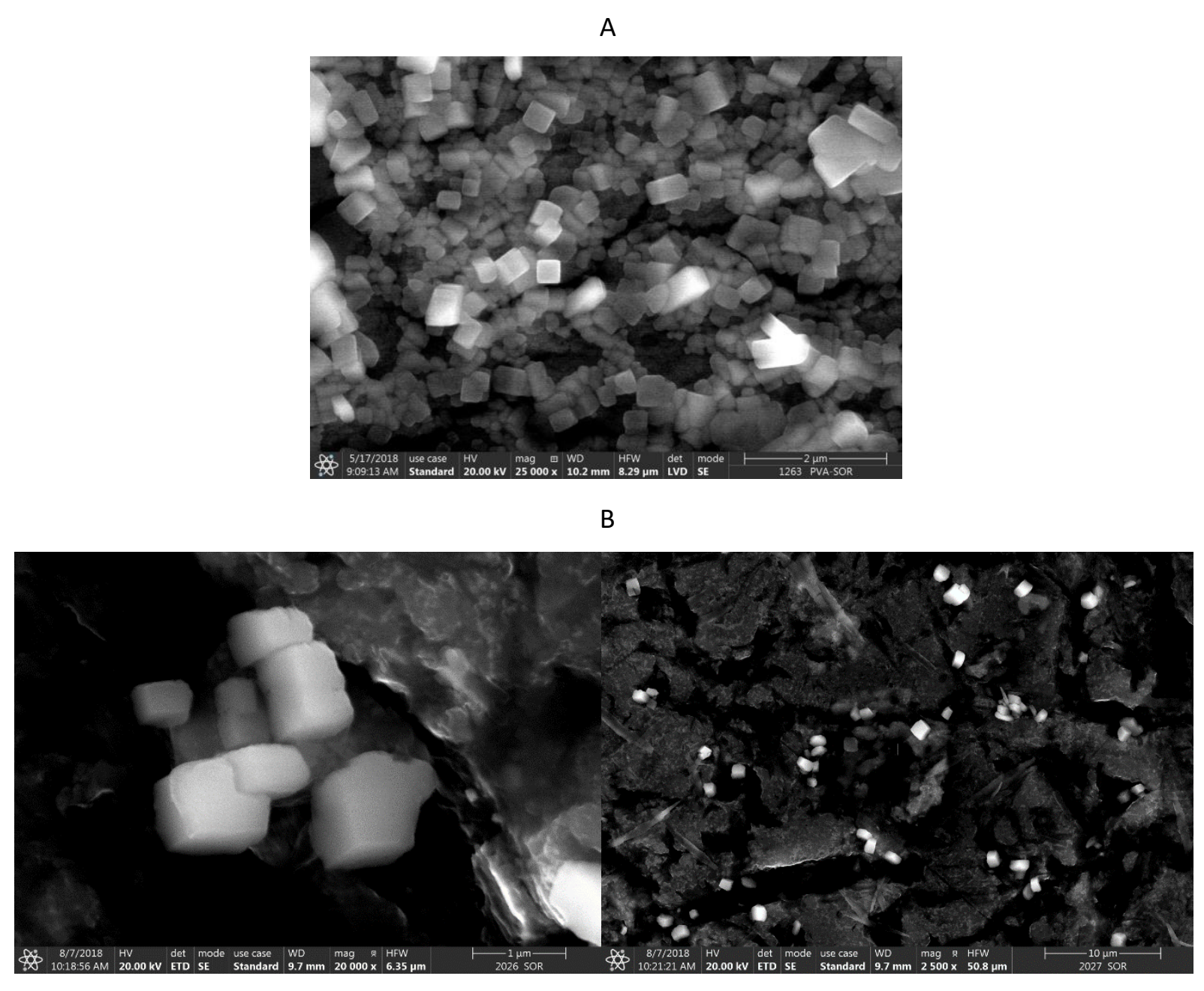

B

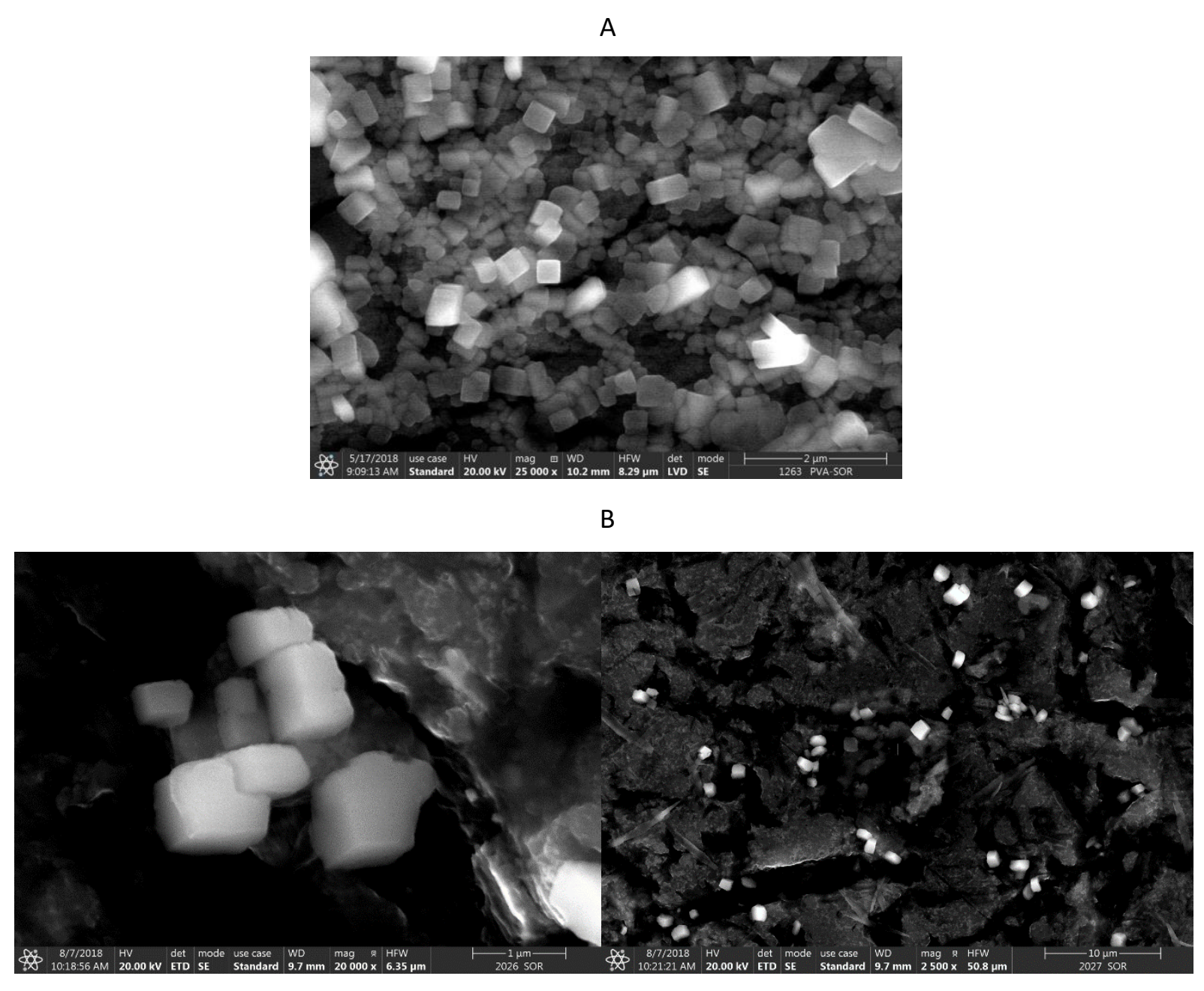

Figure 8

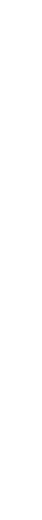

8


Figure 9

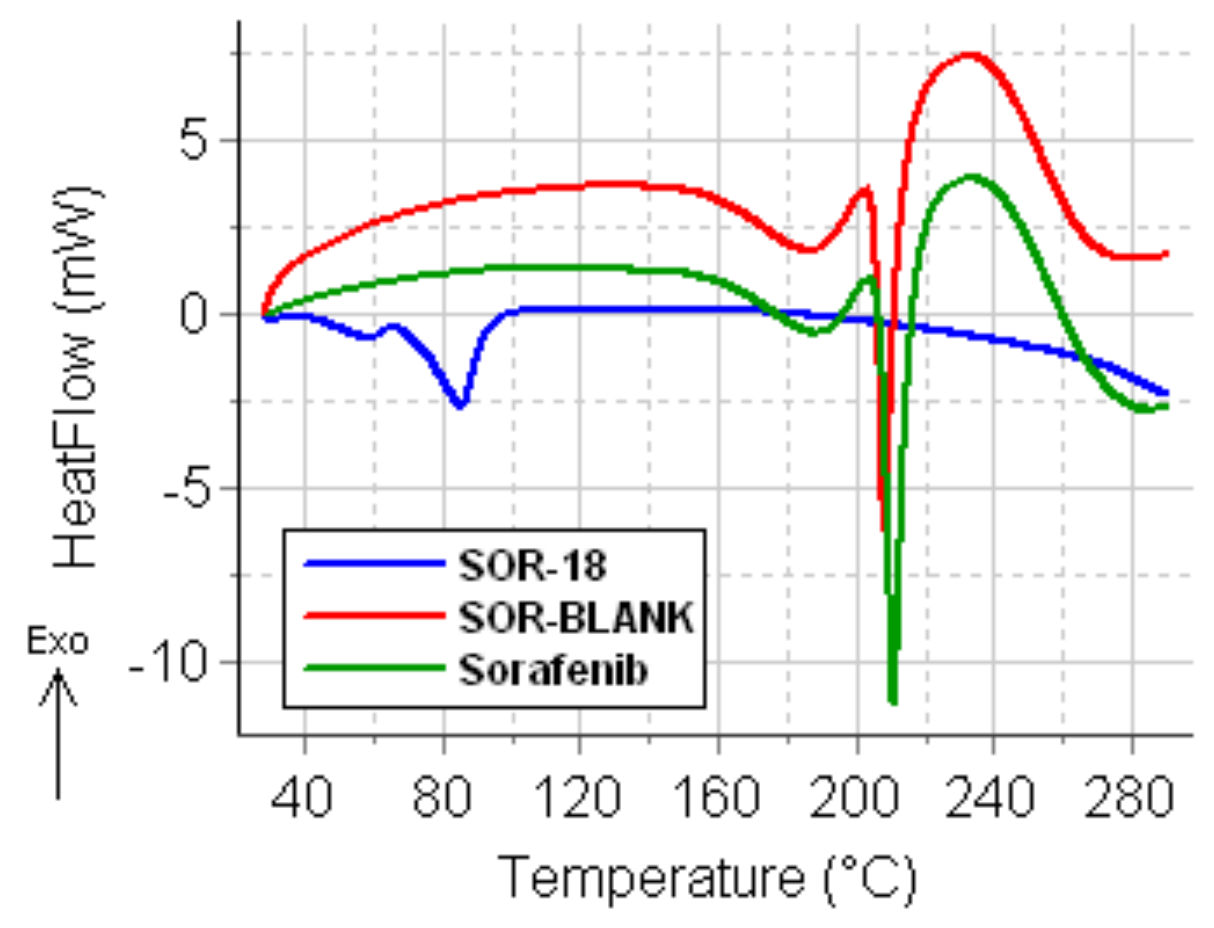




\section{Figure 10}

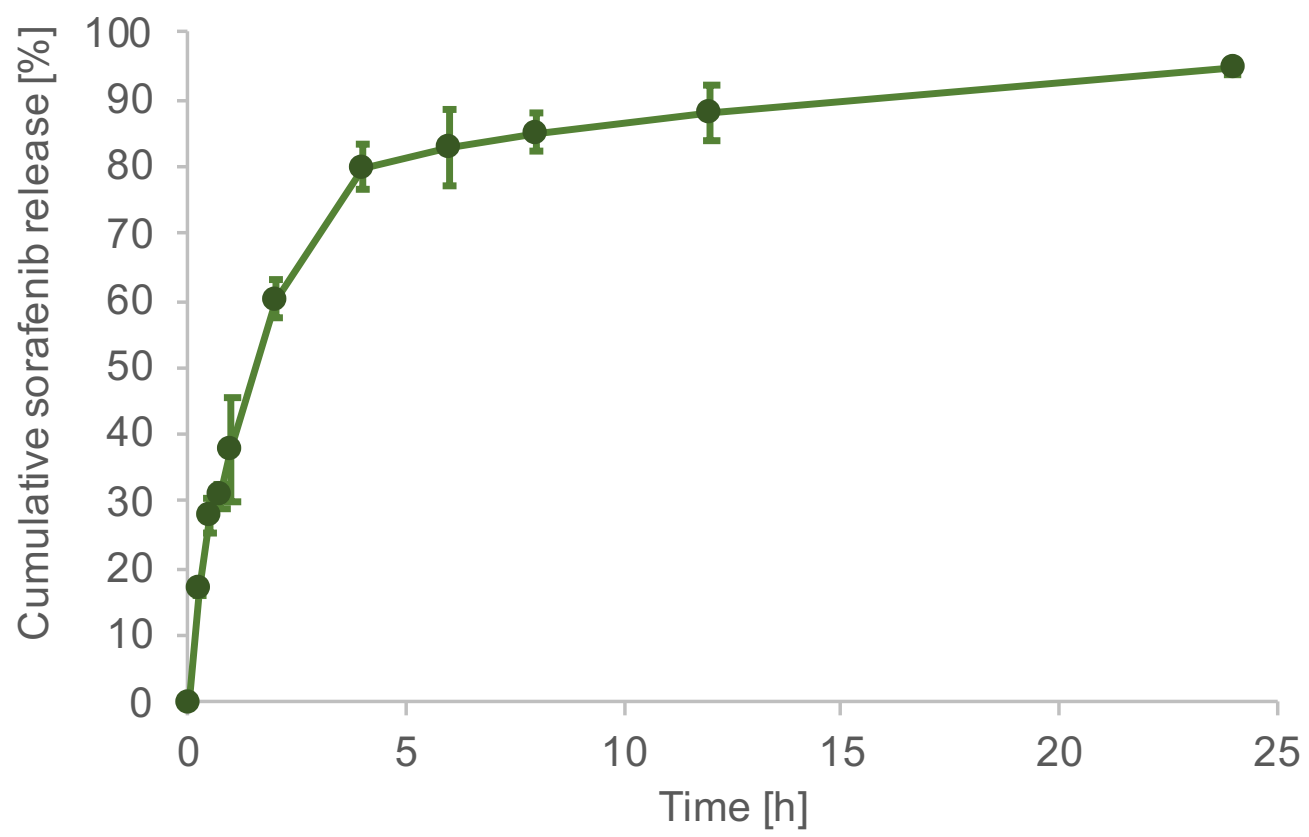


